Journal An-Nafs: Kajian Penelitian Psikologi

http://ejournal.iai-tribakti.ac.id/index.php/psikologi

e-ISSN: 2549-6166

p-ISSN: 2528-0600

\title{
SENTRA MAIN PERAN UNTUK MENINGKATKAN KEMAMPUAN KOSAKATA ANAK DI TK DHARMA WANITA KANDANGAN SRENGAT KOTA BLITAR
}

\author{
Mentari Marwa \\ mentari.marwa@yahoo.com \\ Institut Agama Islam Tribakti Kediri \\ https://doi.org/10.33367/psi.v4i2.933
}

\begin{abstract}
Abstrak
Kosakata merupakan dasar pembentukan kalimat, artinya kalimat tidak akan terbentuk jika tidak ada kata. Semakin kaya kosakata yang dimiliki seseorang maka semakin mudah dalam merangkai sebuah kalimat untuk berkomunikasi baik lisan maupun tulisan.. Populasi dan Sampel dalam penelitian ini anak dengan rentang usia 4-5 tahun dengan kriteria nilai rendah pada skala perkembangan kosa kata. Penelitian ini menggunakan metode penelitian experimental design. Terdapat dua kelompok, yaitu kelompok eksperimen dan kelompok kontrol. Analisis dalam penelitian ini menggunakan uji U Mann-Whitney dan Wilcoxon test. Analisis U mann-Whitney diperoleh hasil rata-rata peningkatan score pada kelompok eksperimen (Mean Ranks pada observasi sesudah treatment adalah 8.00 dan sebelum diberikan intervensi sebesar 5.16) lebih tinggi dibandingkan dengan kelompok kontrol (Mean Ranks pada observasi sesudah treatment adalah 3.00) Hal ini menunjukkan bahwa kelompok eksperimen setelah diberikan treatment atau perlakukan berupa sentra main peran maka subyek mengalami peningkatan kemampuan kosakata lebih baik daripada kelompok kontrol dimana $\mathrm{p}<0.005$. $\mathrm{Z}$ score selisihnya adalah 2,611 sedangkan Wilcoxon $\mathrm{p}<0.005$ selisih Z score adalah 2.023. Hal tersebut menunjukkan ada perbedaan kosakata pada kelompok eksperimen setelah diberikan treatment sedangkan kelompok kontrol tidak mengalami peningkatan dimana $\mathrm{p}>0.005$ dan $\mathrm{Z}$ score 1.761 .
\end{abstract}

Kata Kunci: Kosakata, Main peran, Anak-anak 


\begin{abstract}
Vocabulary is the basic of sentence formation, purpose of sentences will not be formed if there are no words. The richer a person's vocabulary, easier for him/her to arrange a sentence to communicate both orally and in written. This study aims to determine the effect of the application of the role playing center to increase vocabulary for children aged 4-5 years. The population and sample in this study were boys aged 4-5 years with low value criteria on the vocabulary development scale. This study used an experimental design research method. There are two groups, namely the experimental group and the control group. The analysis in this study used the Mann-Whitney $U$ test and the Wilcoxon test. $U$ mann-Whitney analysis obtained the average increase in scores in the experimental group (Mean Ranks on observations after treatment was 8.00and before intervention was given to 5,166) higher than the control group (Mean Ranks on observations after treatment was 3.00) This shows that the experimental group after being treated or treat in the form of a role playing center, the subject experienced an increase in vocabulary skills better than the control group where $p<0.005$. The $Z$ score difference is 2,611 while the Wilcoxon $p<0.005$ difference $Z$ score is 2,023. These show there are differences in vocabulary in the experimental group after being given treatment while the control group did not experience an increase where $p>0.005$ and $Z$ score 1.761 .
\end{abstract}

Keywords: Vocabulary, Role playing, Children 


\section{Pendahuluan}

Institusi Pendidikan Anak Usia Dini (PAUD) memerlukan metode pembelajaran yang mampu menciptakan lingkungan belajar yang nyaman untuk merangsang aspek-aspek kecerdasan pada anak, di antaranya adalah merangsang peningkatan kosakata yang merupakan bagian dari kemampuan berbahasa. Menurut Piaget (dalam Reed, 2007) bahasa merupakan bagian dari perkembangan kognitif dan bahasa memiliki tahapan dalam perkembanga.

Copple \& Bredekamp (1995) Developmentally Appropriate Practices, bahasa merupakan salah satu 5 aspek penting dalam perkembangan pada anak usia 0-5 tahun. Belajar bahasa tidak terlepas dari belajar kosakata, kemampuan penguasaan kosakata memiliki peran yang cukup penting dalam keterampilan berbahasa. Tanpa penguasaan kosakata yang memadai maka tujuan pembelajaran bahasa tidak akan tercapai. Oleh karena itu semakin banyak kosakata yang dimiliki anak semakin terampil pula anak tersebut berbahasa. Penguasaan kosakata merupakan salah satu syarat utama yang menentukan keberhasilan seseorang untuk terampil berbahasa. Kosakata merupakan dasar pembentukan kalimat, artinya kalimat tidak akan terbentuk jika tidak ada kata. Semakin kaya kosakata yang dimiliki seseorang maka semakin mudah dalam merangkai sebuah kalimat untuk berkomunikasi baik lisan maupun tulisan (Soedjito, 2011).

Berdasarkan observasi yang dilakukan oleh penulis dalam proses interaksi sosial di lingkungan sekolah dan dalam proses kegiatan belajar, terdapat anak usia 4 - 5 tahun tidak lancar dalam berbicara. Anak - anak tersebut lebih banyak diam ketika berada di dalam kelas. Ishikawa (2019) ciri-ciri anak yang memiliki kosakata rendah adalah anak tidak mampu berperan sebagai penyimak, tidak memiliki ide dalam berbicara, tidak dapat berpartisipasi dalam percakapan.

Peneliti melakukan observasi pada hari Rabu 24 Juni 2019 pkl 07.30 -09.30 di TK Dharma Wanita Kandangan Srengat dan melihat proses belajar mengajar serta interaksi dalam 
berkomunikasi secara verbal antara guru dengan anak. Terdapat 8 (delapan) anak dari jumlah keseluruhan 21 anak di dalam kelas dengan kemampuan kosakata kurang baik.

Keadaan tersebut ditunjukkan dengan tidak lancarnya anak dalam berbicara, anak cenderung diam saat proses interaksi komunikasi di dalam kelas. Upaya yang dilakukan oleh guru dengan menggunakan metode mengajar yang menyenangkan, ramah, terjalin suasana hangat dan akrab. Keadaan tersebut menunjukkan bahwa tidak terjadi sesuatu hal yang membuat anak menjadi cemas, takut dan ragu-ragu dalam berbicara.

Didukung dengan hasil wawancara yang dilakukan oleh peneliti terhadap guru kelas dan guru pendamping pada Kelompok Bermain tersebut, menunjukkan bahwa selama proses belajar mengajar berlangsung sebanyak 8 (delapan) anak lebih banyak diam dan jarang berbicara, dari waktu ke waktu tidak ada peningkatan. Hasil wawancara juga didapatkan keterangan bahwa anak-anak tersebut berasal dari ekonomi menengah ke bawah di mana kedua orang tuanya sibuk bekerja sehingga kurang adanya intensi komunikasi antar orang tua dengan anak. Darjowidjojo (dalam anonim, 2012) mengatakan kosakata merupakan salah satu komponen yang akan terus berkembang.

Anak yang memiliki kosakata yang baik akan memiliki banyak ide dalam mengungkapkan bahasanya, penguasaan kosakata dalam pembelajaran merupakan kegiatan yang tidak dapat dipisahkan. Peran orangtua dan guru dalam membantu perkembangan bahasa pada anak salah satunya adalah dengan memberikan stimulas kepada anak, mengajak anak berkomunikasi dengan oranglain sesuai dengan taraf perkembangannya, seperti mengungkapkan pendapat secara sederhana. Dari pengalaman peneliti terhadap salah satu sentra yang terdapat dalam metode BCCT (Modul Beyond Center and Circle Time) yaitu sentra main peran maka peneliti tertarik untuk memberikan treatment atau perlakuan kepada anak-anak tersebut sehingga akan terjadi peningkatan kemampuan kosakata. 
Sentra main peran merupakan salah satu sentra yang mengajak anak-anak untuk bermain pura-pura baik menjalani profesi tertentu atau menggambarkan suasana yang menyenangkan ketika berjalan-jalan di kebun binatang, taman bunga maupun di stasiun kereta. Dalam memainkan sentra tersebut anak-anak diharuskan berbicara sebagai bentuk stimulasi dengan cara yang menyenangkan yaitu bermain sesuai dengan taraf perkembangan usianya. Kunci dari sentra main peran adalah komunikasi yang terjalin antar anak, tanpa komunikasi sentra tersebut tidak akan bisa berjalan. Sebelum sentra ini dimulai guru terlebih dahulu memberikan pijakan awal kepada anak dengan beberapa kosakata sesuai tema.

Selama sentra main peran ini berlangsung adalah peran guru sebagai fasilitator dan motivator bagi anak. Konsep belajar yang dipakai dalam metode BCCT difokuskan agar guru sebagai pendidik menghadirkan dunia nyata di dalam kelas dan mendorong anak didik membuat hubungan antara pengetahuan, pengalaman dan penerapan dalam kehidupan mereka sehari hari. Otak anak dirangsang untuk terus berpikir secara aktif dalam menggali pengalamannya sendiri bukan sekedar mencontoh dan menghafal saja.

Selama proses main peran tersebut komunikasi adalah faktor utama terlaksananya sentra tersebut. Tanpa komunikasi maka alur cerita tidak akan terbentuk. Dari proses ini anak akan berkomunikasi dan menjalin dialog dengan teman - temannya yang terlibat dalam permainan tersebut. Anak akan belajar dari pengalaman yang didapatkan.

Kosakata merupakan bagian dari bahasa sebagai sarana kita untuk berkomunikasi. Komunikasi merupakan pertukaran ide atau informasi antara pembicara dengan lawan bicara. (National Council of teachers of English \& International Reading Association dalam Bluiett, 2009).

Penggunaan kosakata selama bermain peran menggambarkan pengetahuan tentang segala sesuatu di dunia, peristiwa-peristiwa dan berbagai macam karakter, anak-anak 
berinteraksi dalam kelompoknya dan memulai mencoba banyak pandangan-pandangan dan bagaimana memisahkan konflik yang terjadi dan apa yang dimaksud, apa yang dikatakan dan apa yang diketahui, hal tersebut dikatakan Vygotsky (dalam Broadhead, 2006).

Anak usia dini dapat berinteraksi sosial melalui sentra main peran. Sentra ini sangat membutuhkan komunikasi yang intensif antara anak yang terlibat dalam permainan tersebut. Tanpa komunikasi maka sentra main peran ini tidak bisa dilaksanakan. Komunikasi membutuhkan kemampuan bahasa yang baik. Setidaknya anak-anak tersebut mampu mengungkapkan pendapat dan kemauannya kepada temantemannya yang lain. Secara bertahap sentra ini akan meningkatkan kosa kata / perbendaharaan kata yang dimiliki oleh anak. Anak-anak yang enggan berbicara diharapkan akan memiliki perubahan positif melalui permainan yang menyenangkan ini.

Kosakata yang akan di stimulasi dalam sentra main peran ini adalah jenis-jenis kosakata yang terdapat dalam teori Nelson \& Darjowidjojo. Sebelum treatment dan sesudah treatment jenis kosakata yang digunakan adalah sama dan diharapkan setelah mendapatkan treatment berupa sentra main peran kemampuan kosakata menjadi terstimulasi dan meningkat.

Penelitian bertujuan untuk mengetahui pengaruh penerapan sentra main terhadap peningkatan kosakata pada anak. Hasil penelitian ini dapat digunakan sebagai referensi bagi pengembangan penelitian mengenai sentra main peran pada model pembelajaran BCCT.

\section{Metode Penelitian}

Metode penelitian ini adalah penelitian kuantitatif dengan menggunakan desain pre test post test control group design. Dalam penelitian ini terdapat dua kelompok, yaitu kelompok eksperimen dan kelompok kontrol dimana kedua kelompok tersebut tidak dipilih secara random. Subjek dalam penelitian ini adalah 8 siswa 
laki-laki dan perempuan dengan rentang usia 4-5 Tahun di TK Dharma Wanita Kandangan Srengat Kota Blitar. Teknik pengambilan sample manggunakan purposive sampling yaitu dengan kriteria nilai rendah pada skala perkembangan kosa kata.

Instrumen dalam penelitian menggunakan alat ukur yang dibuat sendiri oleh peneliti berdasarkan aspek perkembangan kosakata menurut teori (Hurlock, 1972). Alat ukur diberikan kepada subjek sebanyak 2 (dua) tahap. Pertama digunakan diberikan guna untuk mengetahui kondisi awal sebelum diberikan treatment (perlakuan) dan yang kedua adalah diberikan pada saat sesudah treatment (perlakuan).

\section{Paparan Hasil}

Test uji $U$ mann-Whitney menunjukkan rata-rata peningkatan score pada kelompok eksperimen (mean ranks pada observasi sesudah treatment adalah 8.00) lebih tinggi dibandingkan dengan kelompok kontrol (mean ranks pada observasi sesudah treatment adalah 3.00).

\section{Ranks}

\begin{tabular}{|r|l|r|r|r|}
\hline \multicolumn{2}{|c|}{ Kelompok } & N & Mean Rank & Sum of Ranks \\
\hline nilai & eksperimen & 5 & 8.00 & 40.00 \\
\hline & Control & 5 & 3.00 & 15.00 \\
\hline & Total & 10 & & \\
\hline
\end{tabular}

\section{Test Statistics(b)}

\begin{tabular}{|l|r|}
\hline & \multicolumn{1}{|c|}{ nilai } \\
\hline Mann-Whitney U & .000 \\
\hline Wilcoxon W & 15.000 \\
\hline Z & -2.619 \\
\hline Asymp. Sig. (2-tailed) & .009 \\
\hline Exact Sig. [2*(1-tailed Sig.)] & $.008(\mathrm{a})$ \\
\hline
\end{tabular}

a Not corrected for ties.

b Grouping Variable: kelompok 
Mentari Marwa | Sentra Main Peran

Hal ini menunjukkan bahwa kelompok eksperimen setelah diberikan treatment sentra main peran mengalami peningkatan kemampuan kosakata lebih baik daripada kelompok kontrol. Hasil analisis data p $>0.005$ pada kelompok eksperimen dan kelompok kontrol sebelum di beri treatment. Setelah di beri treatment $\mathrm{p}<0.005$. Z score selisihnya adalah 2,611.

\section{Kelompok Eksperimen}

Wilcoxon Signed Ranks Test

\section{Ranks}

\begin{tabular}{|l|l|r|r|}
\hline & \multicolumn{1}{|c|}{$\mathrm{N}$} & Mean Rank & Sum of Ranks \\
\hline posttest eksperimen & 0(a) & .00 & .00 \\
$-\quad$ Negative & $5(\mathrm{~b})$ & 3.00 & 15.00 \\
Ranks pretest & & & \\
eksperimen & & & \\
Positive Ranks & & & \\
Ties & $0(\mathrm{c})$ & & \\
Total & 5 & & \\
\hline
\end{tabular}

Test Statistics(b)

\begin{tabular}{|l|r|}
\hline & $\begin{array}{r}\text { posttest eksperimen - } \\
\text { pretest eksperimen }\end{array}$ \\
\hline Asymp. Sig. (2-tailed) & $-2.023(\mathrm{a})$ \\
\hline
\end{tabular}

a Based on negative ranks.

b Wilcoxon Signed Ranks Test

\section{Kelompok Kontrol}

Wilcoxon Signed Ranks Test

\section{Ranks}

\begin{tabular}{|c|c|c|c|}
\hline & $\mathrm{N}$ & $\begin{array}{l}\text { Mean } \\
\text { Rank }\end{array}$ & $\begin{array}{l}\text { Sum of } \\
\text { Ranks }\end{array}$ \\
\hline posttest kontrol - $\quad$ Negative & $1(\mathrm{a})$ & 1.00 & 1.00 \\
\hline Ranks pretest kontrol & $4(\mathrm{~b})$ & 3.50 & 14.00 \\
\hline Positive Ranks & & & \\
\hline Ties & $0(\mathrm{c})$ & & \\
\hline Total & 5 & & \\
\hline
\end{tabular}

a posttest kontrol <retest kontrol

$\mathrm{b}$ posttest kontrol $>$ pretest kontrol

$\mathrm{c}$ posttest kontrol $=$ pretest kontrol

232 | Journal An-nafs: Vol. 4 No. 2 Desember 2019 


\section{Test Statistics (b)}

\begin{tabular}{|l|r|}
\hline & \multicolumn{1}{|c|}{ posttest kontrol } \\
& - pretest kontrol \\
\hline$Z$ & $-1.761(\mathrm{a})$ \\
Asymp. Sig. (2-tailed) & .078 \\
\hline
\end{tabular}

a Based on negative ranks.

b Wilcoxon Signed Ranks Test

Test uji Wilcoxon menunjukkan ada perbedaan peningkatan kosakata kelompok eksperimen setelah diberikan treatment di mana $\mathrm{p}<0,005$ dan $\mathrm{Z}$ score 2,023. Sedangkan pada kelompok kontrol tidak ada peningkatan kosakata seteleh treatment yaitu p> 0.005 dan Z score 1,761. Dengan demikian hipotesis diterima, bahwa sentra main peran dapat meningkatkan kemampuan kosakata pada anak di Tk Dharma Wanita Kandangan Srengat Kota Blitar.

\section{Pembahasan}

Berdasarkan uji hipotesis dalam penelitian ini diperoleh hasil bahwa ada perbedaan signifikansi antara kelompok eksperimen dan kelompok kontrol sesudah di beri treatment. Analisis U mann-Whitney $\mathrm{p}<0.005$ dan $\mathrm{Z}$ score 2.611. Hasil tersebut menunjukkan sebelum di beri treatment yaitu saat pre test (observasi sebelum treatment) tidak ada perbedaan yang signifikan antara kelompok kontrol dan kelompok eksperimen. Setelah diberikan treatment ada perbedaan. Kelompok kontrol terjadi penurunan dan kelompok eksperimen terjadi peningkatan (mean ranks pada observasi sesudah treatment adalah 8.00) lebih tinggi dibandingkan dengan kelompok kontrol (mean ranks pada observasi sesudah treatment adalah 3.00). Analisis uji Wilcoxon menunjukkan kelompok eksperimen setelah treatment mengalami peningkatan kosakata dimana $\mathrm{p}<0.005 \mathrm{Z}$ score 2.023 sedangkan pada kelompok kontrol tidak mengalami peningkatan dimana $\mathrm{p}$ $>0.005 \mathrm{Z}$ score 1.761 .

Hasil analisis tersebut menunjukkan bahwa kelompok eksperimen setelah diberikan treatment atau perlakuan berupa 
sentra main peran maka subyek mengalami peningkatan kemampuan kosakata lebih baik daripada kelompok kontrol artinya ada perbedaan peningkatan kemampuan kosakata antara kelompok kontrol dan kelompok eksperimen. Kelompok eksperimen lebih tinggi dari kelompok kontrol pada saat observasi sesudah treatment.

Di mana kelompok kontrol diberikan perlakuan berupa sentra persiapan tidak mengalami peningkatan kemampuan kosakata lebih baik dibandingkan dengan kelompok eksperimen yang mendapat perlakuan berupa sentra main peran. Kelompok eksperimen lebih mudah menyerap kosakata baru selama diberikan treatment. Dapat disimpulkan sentra main peran melalui permainan yang menyenangkan akan lebih efektif dalam meningkatkan kemampuan kosakata anak usia 4-5 tahun.

Hal ini didukung oleh penelitian dari Bluiett (2009) bahwa bermain peran memberikan pengalaman nyata kepada anak-anak dalam berkomunikasi. Dua hal yang sangat mendasar dalam main peran adalah pertama kesempatan bagi anak untuk memainkan peran yang berbeda- beda dan kedua kesempatan untuk berkomunikasi secara verbal. Pengalaman main dengan peran yang berbeda beda akan membutuhkan kosakata-kosakata baru sesuai dengan tema peran yang dimainkan. Komunikasi verbal bagi anak-anak adalah kemampuan untuk menggunakan kosakata dalam berkomunikasi dengan teman-temannya. Main peran membutuhkan bentuk komunikasi secara verbal yang akan membangun pengetahuan berupa pengalaman main dan pemerolehan kosakata baru.

Hal ini menunjukkan bahwa kemampuan kosakata dapat ditingkatkan melalui sentra main peran terutama kosakata ekspresif yang dihasilkan oleh anak ketika terjadi komunikasi secara verbal dengan teman-temannya yang berada dalam grup bermainnya. Salah satu aspek yang terdapat dalam main peran menurut Gowen dan Sara Smilansky (dalam PLPG, 2008) adalah komunikasi verbal. Komunikasi ini menghasilkan kosakata dan rangkaian cerita yang ditunjukkan selama main peran. Anak-anak 
akan mengambil peran-peran tertentu sesuai dengan tema yang telah ditentukan. Setiap tema adalah satu kali pertemuan. Tematema tersebut dikembangkan oleh anak melalui komunikasi verbal yang terjadi selama proses main peran berlangsung.

Smilansky, Ruben, Fein dan Vandenberg (dalam Raharjo,2007) mengatakan bahwa bermain pura-pura atau bermain peran merupakan salah satu bentuk permainan yang berfungsi untuk mengembangkan kognitif anak. Menurut Piaget (dalam PLPG, 2008) permulaan dari main peran dapat terlihat dalam perilaku anak-anak yang baru melewati ulang tahun pertamanya. Main peran dicirikan dengan penerapan skema (ide) pada objek-objek di mana skema tersebut tidak dapat diterapkan dalam kehidupan sebenarnya. Piaget menunjukkan bahwa keterlibatan anak-anak dalam tingkat yang lebih tinggi dari main peran dengan teman-temannya sebagai collective symbolism (simbolisme kolektif). Piaget juga menggambarkan percakapan verbal yang anak-anak lakukan sepanjang main peran tersebut akan menciptakan kompromi antara kebutuhan segera dari id dengan kesadaran rasional dari ego sesuai teori dari Sigmund Freud.

Sentra main peran merupakan salah satu sentra yang terdapat dalam metode BCCT. BCCT merupakan suatu metode Pendidikan atau pendekatan dalam penyelenggaraan pendidikan anak usia dini yang dikembangkan berdasarkan hasil kajian teoritik dan pengalaman empirik oleh Creative Center for Childhood Research and Training (CCCRT) di Florida, USA. Metode ini merupakan pengembangan dari metode Montessori, High Scope, dan Reggio Emilio (PLPG,2008). Bermain peran akan mendorong anak-anak yang terlibat di dalamnya untuk berkomunikasi secara verbal. Main peran akan menimbulkan suasana yang menyenangkan pada diri anak. Permainan memungkinkan anak melepaskan energi fisik yang berlebihan dan membebaskan perasaan-perasaan yang terpendam. Main peran merupakan salah satu bentuk dari permainan. Santrock (2002) mengatakan bahwa permainan akan meningkatkan afiliasi dengan 
teman-teman sebaya, mengurangi tekanan, meningkatkan perkembangan kognitif dan meningkatkan daya jelajah.

Hal tersebut menunjukkan bahwa permainan dalam main peran ini mendorong anak untuk bersosialisasi dengan temantemannya sehingga menimbulkan komunikasi. Anak-anak yang sebelumnya pasif dalam main dan lebih banyak diam mulai bisa berinteraksi dengan teman-temannya. Perkembangan kognitfnya meningkat dengan bertambahnya pemerolehan kosakata dan pengetahuan selama proses main peran. Dari uraian tersebut dapat disimpulkan bahwa sentra main peran memiliki manfaat lain selain komunikasi yaitu meningkatkan perkembangan sosial emosional anak. Sesuai dengan pernyataan Hoorn (dalam Partini, 2010) bahwa bermain memiliki peran yang sangat penting dalam mengembangkan kemampuan sosial, berpikir logis, imajinatif dan kreatif. Vygotsky (dalam Santrock, 2010) meyakini bahwa permainan adalah suatu setting yang sangat bagus bagi perkembangan kognitif anak. Dalam kegiatan main peran ini anak menggunakan inderanya untuk menyentuh, melihat, meraba dan mendengar. Anak akan menyentuh melihat dan meraba alat-alat permainan edukatif yang digunakan sebagai properti misalnya dengan menyentuh dan mengusap-usap boneka yang diibaratkan sebagai adiknya, melihat ekspresi teman-temannya dalam berbicara dan mendengar teman-temannya mengajak bicara. Dari penginderaan inilah anak-anak memperoleh pengetahuan, informasi dan pengalaman yang akan meningkatkan kemampuan kosa katanya.

Pada penelitian ini peneliti menggunakan 4 (empat) pijakan dalam menerapkan sentra main peran. Pijakan (Schaffolding) merupakan tahapan-tahapan dalam melaksanakan kegiatan untuk mendukung perkembangan anak. Pijakan (scaffolding) merupakan sebuah konsep dari Vygotsky yang merupakan bagian dari konsep Zone of Proximal Development (ZPD). "The zone of proximal development, or ZPD, one of the most well known of all of Vygotsky's concepts, is a way of conceptualizing the relationship between learning and develpoment" (dalam 
Broadhead, 2006). Keempat pijakan tersebut adalah 1. Pijakan Lingkungan Main. 2. Pijakan Sebelum Main. 3. Pijakan Ketika Main dan 4. Pijakan Sesudah Main.

Suryawati (2012) mengatakan dalam pijakan lingkungan main ini guru sentra menyiapkan alat-alat permainan edukatif, menurut Direktorat PADU (dalam Mulyati, 2009) alat permainan edukatif (APE) adalah segala sesuatu yang dapat dipergunakan sebagai sarana atau media bermain oleh anak yang mengandung nilai pendidikan (nilai edukatif) dan dapat mengembangkan potensi anak. Suryawati (2012) mengatakan alat-alat permainan edukatif terlebih dahulu disesuaikan tema misalnya tema alat-alat komunikasi, disiapkan APE berupa kentongan, gambar kantor pos, telpon, HP, amplop, kertas surat, komputer, seragam tukang pos, topi dll. Persiapan ini dilakukan agar properti benar-benar bisa disediakan secara maksimal sesuai dengan kebutuhan.

Pijakan saat main guru sentra memberikan waktu main 45-60 menit untuk pengalaman main anak dengan tujuan mengembangkan komunikasi yang tepat, memperkuat kosakata anak, memperluas gagasan main anak, meningkatkan kesempatan sosialisasi melalui dukungan teman sebaya, mengamati dan mendokumentasi perkembangan serta kemajuan anak, memberi dukungan pada anak untuk mengembangkan kegiatan mainnya.

Menurut Sujiono (2009) pada hakikatnya anak adalah makhluk individu yang membangun sendiri pengetahuannya. Anak lahir dengan membawa sejumlah potensi yang siap untuk ditumbuhkembangkan asalkan lingkungan menyiapkan situasi dan kondisi yang dapat merangsang kemunculan dari potensi yang tersembunyi. Berdasarkan tinjauan aspek pedagogis masa usia dini merupakan masa peletak dasar atau pondasi awal bagi pertumbuhan dan perkembangan berikutnya. Anak belajar melalui bermain, minat anak dan rasa keingintahuannya memotivasinya untuk belajar sambil bermain serta terdapat variasi individual dalam perkembangan dan belajar. 
Kosakata harus diajarkan kepada anak sedini mungkin agar anak mampu memenuhi sarana tuntutan komunikasi masyarakat penuturnya dalam kehidupan modern (Sugono, 2010). Main peran lebih efektif untuk meningkatkan kemampuan kosakata anak usia 4-5 tahun dibandingkan dengan sentra persiapan. Pengalaman main anak memberikan pengaruh yang besar dalam membangun pengetahuannya. Anak terlibat dalam suasana yang menyenangkan selama permainan. Vygotsky (dalam Santrock, 1995) mengatakan bahwa anak belajar melalui pengalamannya.

Follow up yang dilakukan oleh peneliti adalah memberikan wawasan kepada para guru untuk selalu menerapkan sentra main peran, berkomunikasi dengan para orang tua yang berkaitan dengan kosakata baru. Lebih penting lagi adalah mengadakan parenting yang bertujuan untuk mengedukasi orang tua bahwa stimulasi berbicara perlu dilakukan agar orang tua menyadari pentingnya stimulasi tersebut bagi putra-putrinya dan terwujud kerja sama yang baik antara pihak sekolah dan orang tua dalam rangka meningkatkan kosakata anak usia dini terutama dalam penelitian ini adalah anak usia 4-5 tahun.

Kekuatan dalam penelitian ini adalah bahwa sentra main peran merupakan salah satu bentuk permainan yang cukup diminati oleh anak. Guru mengajarkan anak didiknya dengan memenuhi hak-hak anak tersebut sepenuhnya yaitu melalui bermain. Hal tersebut semakin menarik bila guru sebagai motivator dan fasilitator akan menempatkan fungsinya dengan baik. Bermain merupakan pengalaman belajar yang cukup efektif bagi anak, anak belajar langsung dari pengalamannya sendiri serta menambah pengetahuan pada dirinya. Pengetahuan di sini bisa diperoleh dari peran dan interaksi sosial dalam sentra main peran tersebut. Anak akan belajar melalui dunianya sendiri.

Neuman dan Dwyer (dalam Bintz, 2011) mengatakan bahwa kosakata terus menerus menjadi tujuan penting dalam berkomunikasi. Kemampuan kosakata didefinisikan sebagai 
kemampuan seseorang dalam memiliki kata - kata yang digunakan untuk komunikasi secara efektif dalam berbicara (speaking) dan menyimak (listening).

Beck, McKeown, Kucan, Blachowicz, Fisher, Stahl \& Fairbanks, (dalam Obrochta \& Blachowicz, 2005) memberikan definisi Kemampuan kosakata yaitu kemampuan seseorang dalam menggunakan dan memahami kata - kata ketika mendengar (hearing) dan berbicara (using). Belajar aktif memiliki peranan yang sangat penting bagi seseorang untuk memiliki kemampuan kosakata yang dipergunakan ketika mendengar (hearing) dan berbicara (using).

Jenis-jenis Penguasaan Kosakata menurut Tarigan (dalam Anne, 2012) mengelompokkan penguasaan kosakata sebagai berikut: kosakata reseptif: penguasaan kosakata yang ditunjukkan dengan pemahaman dari menyimak, kosakata produktif: kemampuan menguasai kosakata yang ditunjukkan dengan kemampuan berbicara, penulisan: merupakan indikator dari penguasaan kosakata yang dimiliki oleh seseorang. Pada penelitian ini penulis hanya menggunakan kosakata produktif.

Jenis-jenis kosakata menurut Darjowidjojo (2000) dalam penelitiannya tentang pemerolehan kosakata anak-anak Indonesia membagi kosakata sebagai berikut: 1) kata benda yaitu kata yang menunjukkan benda secara umum contoh : meja, kursi, ibu, adik, sapu dll. 2) Kata Kerja yaitu kata yang menunjukkan suatu tindakan, contoh : menyapu, menggunting, makan dll. 3) kata sifat yaitu kata yang menunjukkan keadaan tertentu contoh : rajin, kurus, gemuk, kencang dll. 4) kata fungsi yaitu kata yang memiliki fungsi tertentu untuk menghubungkan suatu kalimat.

Menurut Soedjito (2011) jenis - jenis kosakata sebagai berikut : a) Kata Umum, b) Kata Khusus. Perkembangan kosakata anak usia pra sekolah adalah berdasarkan status sosial keluarga anak tersebut yaitu : a) Anak - anak dari orang tua yang profesional (parents of profesional) memiliki kemampuan 1100 kosakata, b) Anak-anak dari keluarga kelas pekerja (working class 
families) memiliki kemampuan 650 kosakata, c) Anak - anak dari keluarga sejahtera (welfare families) memiliki kemampuan 400 kosakata. Sesuai dalam penelitian ini menurut Stahl (dalam Loraine, 2008) usia 4 tahun anak memiliki perkembangan kosakata 900 - 1000 kosakata dan usia 5 tahun anak memiliki perkembangan kosakata 1500 - 1600 kosakata.

Hurlock (1978) mengungkapkan bahwa faktor - faktor yang mempengaruhi pemerolehan kosakata anak usia 4- 5 tahun adalah: 1) Kesehatan, anak yang sehat, lebih cepat belajar berbicara dibanding anak yang tidak sehat karena motivasi yang lebih kuat untuk menjadi anggota kelompok sosial dan berkomunikasi dengan anggota kelompok tersebut. 2) Kecerdasan, anak dengan kecerdasan tinggi dalam belajar berbicara lebih cepat dan memperlihatkan penguasaan kosakata yang lebih baik dibandingkan anak dengan tingkat kecerdasan rendah. 3) Keadaan sosial ekonomi, anak dari keluarga ekonomi mampu lebih mudah belajar berbicara, pengungkapan perasaan dirinya lebih baik, lebih banyak bicara, dan lebih banyak mendapat dorongan dan bimbingan untuk berbicara dari anggota keluarga yang lain. Keluarga dengan ekonomi rendah cenderung memfokuskan pada pemenuhan kebutuhan sehari-hari sehingga perkembangan bahasa anak kurang diperhatikan. 4) Jenis Kelamin, anak perempuan lebih cepat belajar berbicara dibanding anak laki-laki. Pada setiap jenjang umur kalimat anak laki-laki lebih pendek dan kurang benar dalam tata bahasa,

kosakatanya lebih sedikit dan pengucapan kata kurang tepat daripada anak perempuan. 5) Keinginan berkomunikasi, semakin kuat dalam berkomunikasi dengan orang lain semakin kuat motivasi anak untuk belajar berbicara dan semakin bersedia menyisihkan waktu serta usaha yang dipergunakan untuk belajar. 6) Dorongan, semakin banyak didorong untuk berbicara dengan mengajaknya berbicara dan didorong untuk menanggapinya akan semakin awal mereka belajar berbicara dan semakin baik kualitas bicaranya. Di sini orang tua khususnya peran ibu sebagai guru yang pertama bagi anak sangat penting untuk membantu 
kemampuan bicara anak. 7) Ukuran keluarga, anak tunggal atau anak dari keluarga kecil biasanya berbicara lebih awal daripada anak dari keluarga besar. Orang tua dapat menyisihkan waktu yang lebih banyak untuk mengajar anaknya berbicara. 8) Urutan Kelahiran, alam keluarga yang sama, anak pertama lebih cepat berbicara dibanding anak yang lahir kemudian. Hal ini karena orang tua dapat menyisihkan waktunya lebih banyak untuk mengajar dan mendorong anak yang lahir pertama dibandingkan anak yang lahir kemudian. 9) Metode pelatihan anak, metode pelatihan ini didapat anak ketika berada dilingkungan keluarga yang bersifat demokratis dan metode pelatihan yang diberikan guru ketika berada di sekolah. 10) Kelahiran Kembar, anak lahir kembar pada umumnya mengalami keterlambatan berbicara. Mereka lebih banyak bergaul dengan saudara kembarnya dan hanya memahami logat khusus yang mereka miliki. Hal ini melemahkan motivasi mereka untuk belajar berbicara supaya dapat dipahami oleh orang lain. 11) Hubungan dengan teman sebaya, semakin banyak hubungan anak dengan teman sebayanya menyebabkan semakin besar keinginan mereka untuk diterima sebagai kelompok sebaya, hal ini akan memperbesar motivasi anak untuk belajar bicara. 12) Kepribadian, anak yang dapat menyesuaikan diri dengan baik cenderung mempunyai kemampuan kosakata yang lebih baik, baik secara kuantitatif maupun secara kualitatif.

Menurut NAEYC (dalam Reed, 2007). Sentra main peran adalah sebuah zona atau area untuk bermain pura-pura yang sangat penting untuk perkembangan kognitif, bahasa, sosial emosional dan perkembangan fisik. Karena dalam bermain peran anak-anak akan mengekspresikan ide, pikiran dan perasaan. Sentra main peran menurut Depdiknas (2006) adalah zona atau area main anak yang dilengkapi dengan seperangkat alat main untuk bermain pura-pura, memerankan tokoh atau karakter tertentu dengan menggunakan empat jenis pijakan (schaffolding) yaitu pijakan lingkungan main, pijakan sebelum main, pijakan saat main dan pijakan setelah main. Penekanan sentra ini adalah alur 
cerita atau skenario sehingga anak dapat berpikir secara sistematis.

Terdapat dua jenis sentra main peran yaitu mikro dan makro. Sentra main peran mikro adalah anak memainkan peran melalui tokoh yang diwakili benda-benda berukuran kecil. Contohnya kandang dengan binatang-binatangan dan orangorangan kecil. Di mana dalam permainan ini anak akan berperan menjadi sutradara. Sentra main peran makro adalah anak memainkan tokoh tertentu dengan menggunakan alat berukuran besar (ukuran sesungguhnya). Contohnya anak memakai baju dan menggunakan kardus besar yang dianggap sebagai mobil-mobilan atau binatang. Di sini anak akan berperan sebagai sutradara sekaligus pemain (Depdiknas, 2011).

Aspek-aspek yang terkandung dalam sentra main peran menurut Gowen dan Smilansky (dalam PLPG, 2008) yaitu Imitation Role Play (Main Peran Meniru), Make-Believe with Objects (Main Peran dengan Objek), Make-Believe in Regard to Actions and Situations (Main Peran Menunjukkan Tindakan dan Keadaan), Persistence (Ketekunan dalam Adegan Main), Interaction (Hubungan), Verbal Communication (Komunikasi Lisan).

\section{Kesimpulan}

Berdasarkan hasil analisis data dan pembahasan terhadap penelitian, maka dapat disimpulkan bahwa hipotesis yang di ajukan dalam penelitian ini di terima, yaitu ada perbedaan kosakata antara kelompok kontrol yang mendapatkan treatment berupa sentra persiapan dan kelompok eksperimen yang mendapatkan treatment berupa sentra main peran dalam meningkatkan kemampuan kosakata anak usia 4-5 tahun. Kemampuan kosakata anak usia 4-5 tahun kelompok eksperimen setelah dilakukan treatment lebih tinggi daripada kelompok kontrol. Hal ini dapat disimpulkan bahwa sentra main peran lebih berpengaruh daripada sentra persiapan dalam meningkatkan kemampuan kosakata. 


\section{Daftar Pustaka}

Anonim, (2008). Effective Vocabulary Instruction Article. Texas : University of Texas at Austin

Bluiett, T.,E. (2009). Sociodramatic Play and Potentials of Early Language Development of Preschool Children. Dissertation. Alabama : University of Alabama.

Bintz, W.,P. (2011). Teaching Vocabulary Across the Curriculum. Journal of Middle School. 3, 44 - 53.

Blachowicz, C.,L.S, Fisher, P.,J, Watts, T., S. (2005). Integrated Vocabulary Instruction Meeting the Needs of Diverse Learners in Grades $K$ - 5. Naperville : Learning Point Assosiates.

Blachowicz, C.,L.,Z \& Obrochta, C. (2005). Vocabulary Visits: Virtual Field trips for Content Vocabulary Development.Journal of Internasional Reading Association, 59, 263.

Broadhead, P. (2006). Developing of Understanding of Young Children's Learning Through Play : the place of observation, interaction and reflection. Journal of British Educational Research Association. 32, 191 - 207

Copple C \& Bredekamp S. (1995). Developmentally Appropriate Practice, Washington : NAEYC

Departemen Pendidikan Nasional, (2005). Kamus Besar Bahasa Indonesia. Jakarta : Balai Pustaka.

Departemen Pendidikan Nasional. (201). Pedoman Pendekatan "Beyond Center and Circle Time (BCCT)" (Pendekatan Sentra Dan Saat Lingkaran) Dalam Pendidikan Anak Usia Dini. Jakarta : Direktorat Pendidik Tenaga Kependidikan Pendidikan Nonformal.

Elvana \& Luluk. (2012). Meningkatkan kosa kata anak usia 3-4 tahun melalui sentra main peran. Tesis. Semarang: Program Magister Psikologi. Program Pasca Sarjana. Universitas Katolik Soegijapranata.

Hurlock, E.,B. (1972). Child Development Fifth Edition. Johannesburg: Mc Graw - Hill.

Ishikawa, S (2019). A Reconsideration of the Construct of "A Vocabulary for Japanese Learners of English": A Critical Comparison of the JACET Wordlists and New General Service Lists (1) 
Mulyati, M. (2010) Penggunaan Alat Permainan Edukatif: Upaya Membantu Perkembangan Bahasa dan Kognitif Anak Usia 3 - 6 Tahun. Jurnal edukatif, $6.65-72$

PLPG. 2008. Pendidikan di PAUD. Malang : PSG Rayon 15 Malang

Rahardjo, B. 2007. Aplikasi Teori Bermain untuk Anak Usia Sekolah. Jurnal Didaktika. Vol.8 h 262 - 267.

Reed, S. 2007, The Importance of Symbolic Play as a Commponent of Early Childhood Curriculum. Journal of Essays in Education. Vol. 19, h.37 - 45.

Santrock, J.W.1995. Life - Span Development. Jakarta : Erlangga.

Soedjito, 2011. Kosakata Bahasa Indonesia. Jakarta : Aditya Media.

Sugono, D. 2010. Pengembangan Kosakata Bahasa Indonesia dalam Memasuki Globalisasi. Jurnal Kandai. Vol 6 h. 111 118.

Sujiono, Y. N. 2009. Konsep Dasar Pendidikan Anak Usia Dini. Jakarta: Pusdiani Press UNJ.

Suyadi, 2010. Psikologi Belajar PAUD. Yogyakarta : Pedagogia.

Tarigan, HG, 2008. Berbicara Sebagai Suatu Keterampilan Berbahasa. Bandung : Angkasa.

Tarigan, HG, 2008. Menyimak Sebagai Suatu Keterampilan Berbahasa. Bandung : Angkasa.

Templeton, S dan Pikulski, J.J, 2004. Teaching and Developing Vocabulary: Key to Long-Term Reading Success Research. Nevada : Houghton Miffling Company. 